\title{
Learning English in Tourism and Hospitality Internships Overseas: Reflections from Six Taiwanese College Students
}

\author{
Yi-Hsuan Lin $^{1} \&$ Yu-Ching Tseng ${ }^{2}$ \\ ${ }^{1}$ English Department, Chinese Culture University, Taiwan \\ ${ }^{2}$ English Department, Tamkang University, Taiwan \\ Correspondence: Yu-Ching Tseng, English department, No. 151, Yingzhuan Rd., Tamsui Dist., New Taipei City \\ 25137, Taiwan. E-mail: ychtseng@mail.tku.edu.tw
}

\author{
Received: May 1, $2020 \quad$ Accepted: May 31, $2020 \quad$ Online Published: June 2, 2020 \\ doi:10.5539/ijel.v10n5p1 URL: https://doi.org/10.5539/ijel.v10n5p1
}

\begin{abstract}
The purpose of this study was to examine the overseas internship experiences and determine whether they helped to enhance the intended English learning outcomes for students who will be working in the service industry. Seventeen entries of reflective journals written by six students who interned overseas were analyzed. The participants reported their frustrations in language learning and described how these experiences could complement their overall career development in the future. The students identified a gap between everyday language needs in the industry and their language training received in Taiwan. The results indicated that the participants thought the English courses in Taiwan have disproportionately emphasized reading or writing skills, whereas speaking and listening were in high demand in the workplace, particularly given the difficulties occurring in cross-cultural communication. The analysis also indicated that the participants' oversea working experiences positively affected their English learning motivation. These experiences also helped the participants notice differences in interactions with people from various linguistic backgrounds. English learning in Taiwan is traditionally embedded in English as a foreign language (EFL) classrooms that are reading/writing-centered and examination-oriented. The course content should be revised to improve students' oral communication skills for the workplace.
\end{abstract}

Keywords: English for specific purposes, tourism and hospitality, overseas internship

\section{Introduction}

The tourism industry is a major pillar of Taiwan's economy. A growing number of high school graduates choose to major in tourism and hospitality in order to fast-track into skilled careers. Taiwanese colleges cooperate with overseas international companies to offer students overseas internship job opportunities before they graduate. Internships are gaining popularity as an instrument for students' workplace learning and job searching (Liu, Xu, \& Weitz, 2011). That is, internships help to facilitate the transition between attending school and securing a job.

International hospitality internships offer students direct experience in the travel industry. With a general trend of global travel on the rise, a tourism internship abroad provides students a deeper understanding of how to cater to international clientele. The ability to communicate in English is imperative for those working in an English-speaking country. In Taiwan, English is not the primary or secondary language spoken outside of the English classroom. English is regarded more as a subject in school than as a means of communication. For most Taiwanese students, English is learned in the classroom setting, and they do not have keen interest in using English outside of school. Despite a proliferation of English-learning opportunities, most Taiwanese students in occupational schools continue to have low English proficiency.

The purpose of this research was twofold. First, the researchers sought to understand the complex ways in which an experience of working abroad may benefit a student's English development in a future profession. Second, to understand how the language exposure, characterized by features such as English language contact and participation in social activities in the second language environment, would facilitate language learning. This study documented how these students perceived their vocational language needs in an overseas setting. By addressing language needs from the students' perspective, English teachers can be alerted to the needs and changes of the industry on an international scale, and consequently, a more comprehensive curriculum design for 
a multidimensional English for specific purposes (ESP) program for tourism and hospitality can be implemented.

\section{Literature Review}

Over the past hundred years, the development of vocational education has made significant contributions by supplying a large workforce to promote and support economic and industrial development in Taiwan. Given the context of global competition, the importance of English is highly emphasized in these vocational-track programs.

\subsection{Previous Studies on English Learning in Tourism and Hospitality}

English is the lingua franca in international tourism and hospitality contexts. Previous studies on tourism and hospitality English have explored language issues from the perspectives of three stakeholders: industry (or employers); teachers (universities); and students (learners). Some research has tried to identify industry requirements, addressing issues of language needs from employers' perspectives (Bruton, 2009; Leslie \& Russell, 2006; Martin \& Davies, 2006). Some other studies have discussed curriculum design and tried to establish synergies between industry and university in order to design language courses that suit students' tourism job development (e.g., Kirkness \& Neill, 2009). Others have investigated the effectiveness of curriculum design from both teachers' and students' perspectives (Lo \& Sheu, 2008; Luka, 2009).

As students are the major stakeholder in this triangular partnership, studies focused on students' needs generally address different aspects of language skills. While some have attempted to bridge students' communication across language or cultural barriers (e.g., Becket \& Brookes, 2012), others have focused on finding ways to develop students' writing (Haggag, 2008). Still others have tried to improve students' language skills and increase their motivation by adding interactive elements through computer-based activities (Laborda, 2009).

\subsection{On-the-Job English Learning}

Taiwan is an English as a foreign language environment. Most occupational students are not diligent enough to study English if not requested by teachers, as English is not their medium of communication outside the classroom. When students intern in an English as a second language (ESL) country, they immediately face an English environment. They obtain experiences in an environment that is different linguistically, culturally and socially than their study or work contexts in Taiwan.

Experience is crucial in any learning process (Legutke \& Thomas, 1997; Mason, 2002). Beard (2006) defined experiential learning as "the sense-making process of active engagement between the inner world of the person and the outer world of the environment" (p. 19). From students' perspective, working abroad is a learning experience that is spontaneous and autonomous, as language learning is not confined to the traditional classroom but results from the unique relationships developed in students' work or daily lives. Internships abroad can be referred to as experiential learning grounded in constructivism. Real-life occupational English can be constructed through their on-the-job interactions. Students put into practice in the real world what they have acquired in the classroom or test whether tourism and hospitality theories have matched their new working environment.

\subsection{Linkage Between Work Experiences and Informal Learning}

Learning takes place in a wide variety of settings because learning can result from daily activities, especially at work. The term "informal learning" was first used in the published literature by Knowles (1950) in his book. One important feature of informal learning is its basis in experience. The way that an individual makes sense of his/her daily life can be considered informal learning (Watkins \& Marsick, 1992), which is also referred to as experiential or incidental learning (Cedefop, 2008, p. 93).

In Eraut's $(2004,2011)$ studies, he established a close linkage between work and informal learning. In fact, the relationship between work and learning was considered likely to be interchangeable. Experiential learning, which arguably constitutes most of the learning that occurs in the workplace, represents the groundwork for adult learning theory (Watkins \& Marsick, 1992). According to Anderson, Boud and Cohen (1995), "the ultimate goal of experiential learning involves the learner's own appropriation of something that is to them personally significant and meaningful" (p. 208). In the literature, informal learning is considered a necessary context for human development and is indispensable for effective learning (Hall, 2009).

\subsection{Overseas Informal Language Learning}

In second-language acquisition, informal learning is also associated with language gains (Inozu, Sahinkarakas, \& Yumru, 2010). For overseas informal language learning, importance should be placed less on documenting language learning outcomes and more on what students do, or fail to do, with the second language. Attention to language learning in non-educational informal settings usually highlights the necessity to consider learning not 
only as an individual process but also as a social and cultural process. Many studies have claimed that language learning is grounded in the theoretical framework of the sociocultural theory of Vygotsky. This theory asserts that meaningful interaction among people serves as the greatest driving force in language learning (e.g., Lantolf \& Appel, 1994; Lantolf \& Thorne, 2006).

English use has always involved the interplay of users' dispositions and those of their interlocutors. Previous research on students' study abroad experiences has focused on their social interactions (Wilkinson, 2002; Zimmerman, 2011), whereas other works have focused on the influence of studying abroad on language identities or the ways it might be mediated by race, gender, and nationality (Benson et al., 2012). According to Huebner (1995), "the overseas experience seemed to result in a much wider variety of performances and behaviors among students than does study at home" (p. 191). How the multifaceted nature of informal learning of English in a working context helps create diverse learning experiences that contribute to an individual's language development is an interesting issue to explore.

Internship experiences can make a positive and sustainable impact because these experiences of learning English differ from those gained in the classroom. This study aimed to describe where and how learning occurred, as these experiences can be educationally valuable. The participants were asked to describe their lives overseas and their language learning experiences during their internship in written reflection journals.

\subsection{Reflective Process in Learning}

Reflection in education contexts is regarded as a problem-solving activity. Graham Gibbs (2013) depicted reflective thinking as a cycle that contains distinct stages, as shown below:

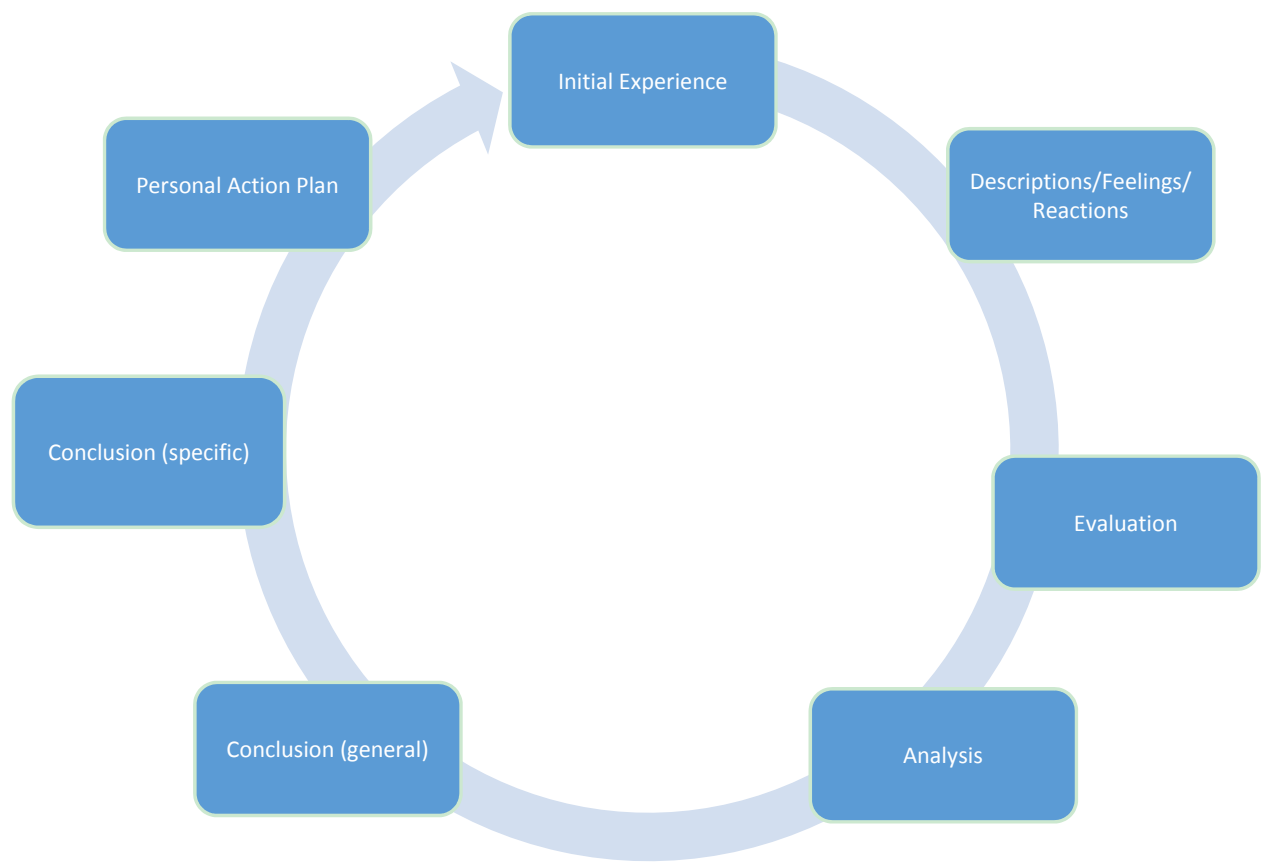

Figure 1. The reflective learning cycle (Gibbs, 2013, p. 50)

Work abroad experiences provided an opportunity to investigate students' English learning beyond the limitation of traditional learning pedagogy. These experiences challenged students in ways not typically experienced in the classroom setting. Considering that most of the traditional assessment tools may not be appropriate in a work abroad setting, a retrospective report in the form of a reflective journal was used as an alternative evaluation to contextualize the process of learning.

\subsection{Using Reflective Journals to Document Internship}

Journaling and reflective thinking are recognized as effective tools in language learning (e.g., Holmes \& Moulton, 1995; Nassaji \& Cumming, 2000). Reflection is also an important cognitive process in workplace learning; however, students engaged in overseas internship rarely reflect upon their own initiative, as they are overwhelmed by their heavy workload. Upon request, the students in this study had to upload their writing 
reflections using the applications Facebook and Line. The purpose of writing reflections is to engage students in the habit of linking a current experience to their learnings.

With social media, the students' journal entries could gain a social dimension with a continuous feedback loop that benefits all students within the group or helps teachers understand their lives overseas. The very nature of this medium could foster connections and promote timely communication with the students' instructor and peers. As Mortensen and Walker (2002) asserted, expressing one's feelings on a private social media site allows writers to develop their own voice. The reflective postings enabled students to express their feelings, seek emotional support from their peers, and reflect on their workplace learning.

As Dewey (1933) noted, learning requires open-mindedness and a willingness to listen to others and act upon criticism. This is especially true in the workplace. Interns working abroad should respond internally to criticism in order to improve their job performance, since intrinsic motivation is considered a critical feature of informal English learning at work (Evans \& Waite, 2010). Quantifying student improvement may be difficult. Each individual has a different learning curve and matures at different times when they encounter different workplace situations.

Learning experiences outside the classroom are inherently interdisciplinary. The internship abroad program provides researchers with an extra pair of disciplinary lenses uniting language preparation and tourism industry needs, which might enrich tourism English teaching approaches. The purpose of this study was to describe students' perceptions of their internship experiences during a credit-based work abroad program organized by a vocational-oriented college in Taipei. A year or two semesters abroad at one of the university-selected companies to train students' intercultural communication skills every day could have provided language teachers insights into preparing ESP courses in tourism. The following questions concerning English communication and tourism skills specifically applied to the international tourism industry:

1) Are language or nonlanguage difficulties reported more frequently by students during their internship?

2) What kind of language difficulties, i.e., speaking/listening or reading/writing, do these intern students encounter most frequently during their internship?

3) Are language or nonlanguage skills reported as more frequently learned abilities by students when working abroad?

4) What kinds of skills/strategies do students learn during their internship?

5) Did the English preparatory classes in Taiwan help students overcome these language difficulties?

6) To what extent do students perceive their work abroad experiences as supporting their English learning?

\section{Method}

\subsection{Background of Internships}

The students majoring in tourism and hospitality at a vocational-oriented college in Taipei were given the opportunity to participate in a one- to two-year internship program that required them to work in companies related to the tourism industry in overseas countries. Students could choose to go to Australia or Singapore. The working opportunity was arranged by the college. Apart from earning credits, the goal set for the students was to earn practical experience in the industry and to familiarize themselves with a foreign culture and language. Among the 17 students who worked abroad, 6 agreed to participate in this study. The participants' English skills were tested in their first year, as specified in the next section.

\subsection{Internship Placement}

The college committee board conducted the preliminary interview to ensure the applicants were physically and mentally healthy to work away from home. After the interview, the hiring companies conducted another individual interview through recruitment agents. Most of the intern students were placed in international companies that required both Chinese and English. For the overseas internship opportunities, the students' English proficiency level was not the main concern of the companies. Most companies emphasized their working skills, and their willingness to learn at work.

\subsection{Participants}

All of the participants in the present study were 19- to 21-year-old second-year college students. As shown in Table 1, the students' backgrounds indicated that four students who agreed to participate were females and two were males. Two went to Australia, and four went to Singapore. Their English language proficiency on the common European Framework of Reference for Languages scale ranged from A2 to B1 as shown in the Test of 
English for International Communication (TOEIC) scores, which is produced by the Educational Testing Service.

Table 1. Background information on the learners

\begin{tabular}{|c|c|c|c|c|c|}
\hline $\begin{array}{l}\text { Students (Pseudo } \\
\text { Name) }\end{array}$ & Gender & TOEIC Score & Country & Internship Host Company & Jobs \\
\hline $\mathrm{Yu}$ & Female & 430 & Australia & Chinese chain restaurant at a city center & Waitress \\
\hline Wei & Female & 410 & Australia & Chinese chain restaurant in a suburban area & Waitress \\
\hline Shen & Male & 330 & Singapore & Airport duty-free shop (chocolate) & Sales clerk \\
\hline Andy & Male & 605 & Singapore & International hotel & Housekeeper \\
\hline Chia & Female & 310 & Singapore & Barbeque house & Waitress \\
\hline Ching & Female & 460 & Singapore & Airport duty-free shop (cosmetics, perfume, etc.) & Sales clerk \\
\hline
\end{tabular}

As shown in Table 1, the participants' jobs would enable them to gain practical hands-on experience and opportunities to practice English in the service industry. Talking and listening in English would certainly occur in the process of communicating with guests and supervisors. Some intern students were requested to handle reservations, took incoming phone calls, or noted reservations and special requests from guests. English would be used a great deal if the intern students tried to anticipate and respond to guest needs and maintain positive guest relations.

\subsection{Data Collection}

All of the participating students had experience in writing reflective journals during their part-time jobs in Taiwan. In this study, the students understood that the reflective journal would help them observe and record their daily work practices in order to seek future improvement, including improvement in both their linguistic and non-linguistic abilities. The intern students were asked to write reflections regarding their work adjustment and English performance at least once per month. The participants could post their reflective writing in the online chat room to discuss with their fellow classmates or send them directly to their instructor. The instructor evaluated their workplace performance, monitored their progress, provided suggestions, and thus acted as an intermediary between their working and learning processes.

The following guidelines (Gibbs, 2013) for the required elements of journal writing were provided to the students.

Description: What happened?

Feelings: What were your reactions and feelings?

Evaluation: What was good or bad about the experience?

Analysis: What sense can you make of the situation?

Conclusions (general): What can be concluded, in a general sense, from these experiences and the analyses you have undertaken?

Conclusions (specific): What can be concluded about your own specific, unique, personal situation or way of working?

Personal action plans: What will you do differently in this type of situation next time? What steps will you take based on what you have learned?

A total of 17 entries from the participants were obtained during the 3-month data collection period of their internship. Only two entries were made public in the chat room by two of the students to share with their classmates; the rest of the journal writings were private entries submitted only to the instructor. Keeping a reflective journal can be a challenging task for intern students. Most of the students were working more than 50 hours per week. Given the students' lack of time and their lower English proficiency, the instructor allowed them to write their journals in Chinese. In addition, to enrich the data, the interactive feedback and conversations between and among the instructor and students were also analyzed.

\subsection{Analysis of Data}

Thematic analysis was conducted following the general principles of Riessman (1993) in writing personal narratives. The students' reflective journal writing was considered a personal narrative in which they remember, argue, convince, and engage their readers (Bamberg \& McCabe, 1998). In this study, a data-driven approach was 
adopted. The researchers coded the prevalence of the data items by counting the frequency of terms that appeared in the journal postings or that were articulated in the follow-up chat-room dialogues across the entire data set. The coded items in the content of the students' journal reflections were further analyzed and categorized into groups. The researcher filtered the most frequently found terms and categorized the synonymous terms into the same category. The themes and subthemes were identified by processing the most frequent terms coded from the students' texts. Themes and subthemes, referring to the aspects most frequently mentioned by the students when thinking retrospectively and narrating their past experiences, were captured.

In the narratives of students' working experiences, a variety of binary adjectives were found, such as bad-good. Among the adjectives, the difficult/easy contrast pair appeared frequently in journal entries. This pair was the most prominent one. Since the students have strong emotions toward their working surroundings and language learning experiences, two of the following categorizations were circled around "difficulties," such as language learning difficulties and difficulties encountered in general.

The search for professional terms or behavior patterns that are common to the dialogue of the service industry revealed that the narratives reflect a broad use of coping strategies or skills to make their job easier. The intern students use a range of skills that allowed them to accomplish their work objectives. For example, they reported learning from senior students, mingling in social situations with co-workers or establishing friendships with roommates.

As explained in Table 2 in the following section, the themes were grouped into seven main categories: nonlanguage difficulties; language difficulties; language skills; nonlanguage-related skills; professional-related skills; work-related plans; and lifestyle change. The researcher further organized these categories under three general issues: difficulties encountered; skills (or strategies) learned; and future plans.

\section{Results and Discussion}

This study adopted a qualitative approach to gauge the concerns of the students from the 17 postings. The results of the analysis were discussed from three perspectives: the difficulties students encountered; the skills learned; and their plans for the future. Two kinds of difficulties are identified, including those associated with either language or nonlanguage-related issues. Nonlanguage-related issues can be further broken down to include the topics of daily survival, social roadblocks and cultural roadblocks. By contrast, language difficulties are divided into oral skills (speaking/listening) and writing skills (writing/reading). Under the theme of speaking and listening, the subthemes included conversation length, foreign accents, sentence structure/appropriate usage, and vocabulary/terminology. Regarding the theme of reading and writing, even though these skills were mentioned less by the students, the issues touched upon included reading contracts and manuals for electronic appliances and some miscellaneous issues.

The second category emphasizes the skills learned, which include three major themes: listening and speaking skills; reading and writing skills; and problem-solving skills. The fourth theme appearing from the students' reflective journal writing is related to their work skills in the professional field. They mentioned their increasing speed and physical strength at work, the ability to handle customer complaints, and their greater attention to detail.

Finally, the third category concerns future plans. Some students mentioned that their future development was planned or modified because of the internship experience, including work-related plans and lifestyle changes. 
Table 2. Categorizations of the themes appearing in the journals

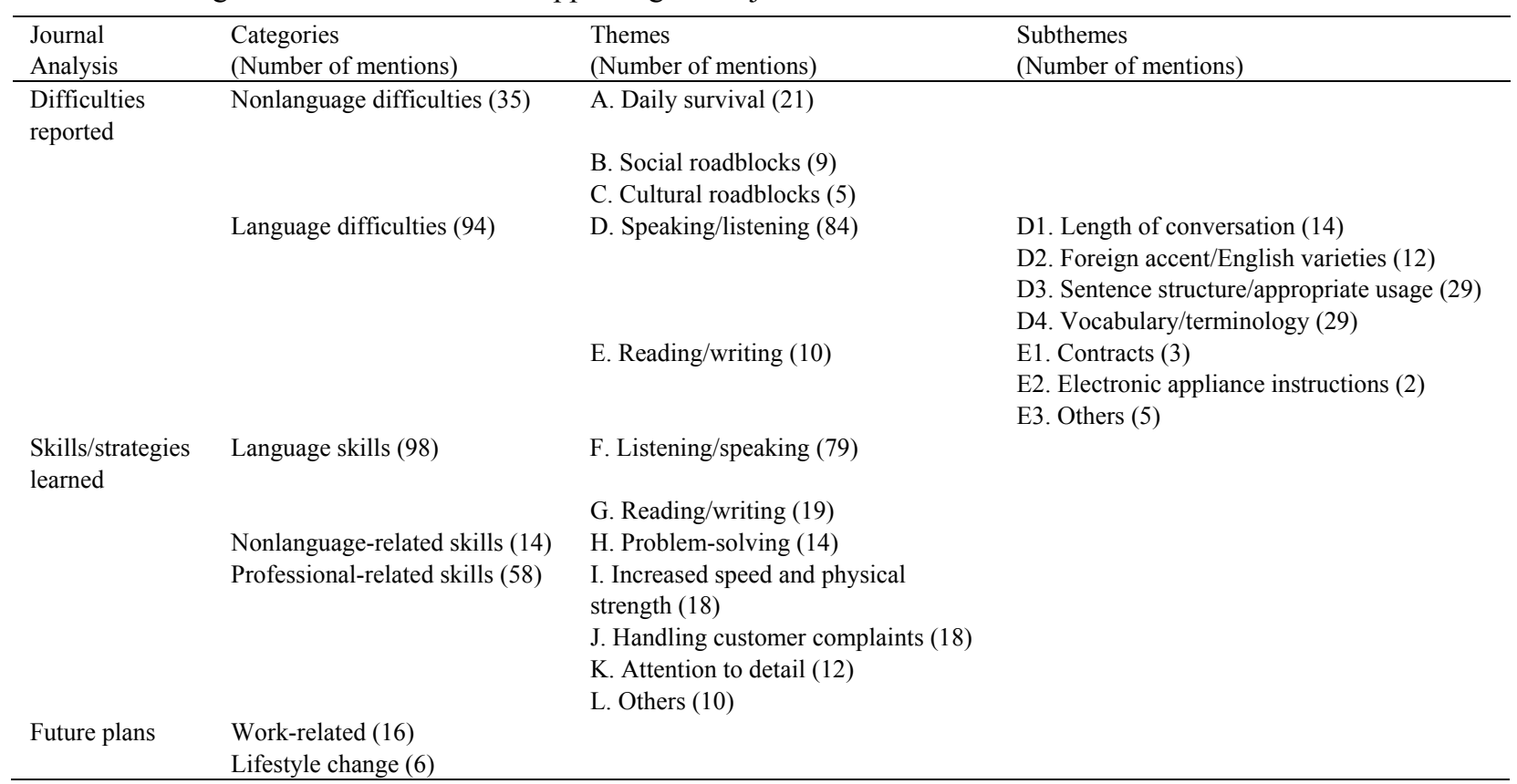

\subsection{Difficulties Reported}

\subsubsection{Nonlanguage-Related Issues}

The participants reported that difficulties arose in their work and daily lives. Most of the intern students consulted seniors from their college who were still on an internship in the same country. Having access to someone who spoke the same language seemed essential to the new interns, as they reported reduced stress and time saving from this contact. They believed that seeing a familiar Taiwanese face helped eased some of their psychological burden.

\subsubsection{Daily Survival}

The following are some excerpts in which they mentioned the difficulties they encountered. In the first excerpt, the student needed survival skills, as she was new to the public transportation system. Even though the following anecdote was categorized as a nonlanguage-related issue, her anxiety was compounded because she was in an environment that demanded use of the language in which she was not proficient, so she retreated into the Chinese-speaking environment when she could.

I arrived in Australia in the middle of the night... I was staying with a senior intern from my school for a week because my apartment wasn't ready until next week. I went to work with Sandy... She showed me the bus schedules and how to load funds onto my bus ticket... She took me to work the first couple days. (Wei, submitted in week 3)

... At first, I knew where to get off the bus by recognizing the buildings around the bus station. Gradually, I started to notice the store signs and some English words and knew where I was. I knew enough to get off the bus at the right places when I needed to... well, I visited Chinese stores most often, because that doesn't require too much English anyway. (Wei, submitted in week 4)

\subsubsection{Social and Cultural Roadblocks}

The intern students faced difficulties when trying to socialize at work. Sometimes the intern students were required to attend the social events held by the company where they worked. The students reported that Western people communicate in different patterns. They had limited conversational topics to talk about. They did not know how Westerners chat.

The following gift-giving interaction indicated that the student's Australian co-worker expected her to open the gift immediately to show her appreciation. However, people in Taiwan are not used to opening gifts right away:

My major difficulty at work is now "making friends." How to make friends with my fellow co-workers? We saw each other a lot. But we barely talked; she was an Australian, and we worked the same shift. Well, 
not just her, I don't know how to chat with my Australian co-workers. This week, we had this event at work where we exchanged gifts with co-workers. I didn't open the gift my co-worker bought me right away, but she opened mine immediately. She seemed to think I did not like her gift. Well, it was not like that. I just felt embarrassed unwrapping a gift in public. (Yu, submitted in week 4)

\subsubsection{Language-Related Issues}

\subsubsection{Listening and Speaking Difficulties}

In the workplace, language problems were frequently reported in communicating with customers and co-workers, especially when the situation involved oral communication. The intern students found it difficult when sentences became overwhelmingly long. The following is what $\mathrm{Yu}$ wrote in her journal. This particular event happened in week 5 of her internship in a downtown Chinese restaurant, where half of her guests were Chinese-speaking and the other half were English-speaking. She evaluated the situation and decided to write about this event in her journal.

\section{Length of Conversation. Longer conversations might be problematic for the interns.}

This Aussie is a returning customer; I have seen him several times. I think he knew that I am a regular waitress here. I have not served him before. This week, he talked to me for the first time. He saw that the Chinese guest at the next table was using coupons, so he asked me how to get discount coupons. I knew the rules for discounts by heart in Chinese. But I have never explained such complicated things in English. So, I hesitated... Well, the rules are that "with a prepaid 100 dollars in cash, you get 110-dollar worth of coupons. Coupons are in effect the day of your purchase. But you cannot use them together with the membership discount." When I saw him taking out the membership card, I suddenly panicked. (Yu, submitted in week 5)

Foreign Accent/English Varieties. In the analysis, all the students who interned in Singapore noted a broad problem when communicating with supervisors or co-workers who have a strong local English accent. Taiwanese students generally considered it difficult to comprehend the pronunciation of English varieties that diverge drastically from the standard form of American English. Shen, one of the interns who worked at the duty-free shop, wrote:

I knew the routines. What troubled me is that I am having a hard time understanding my Indian supervisor's English. I guess it would take me a lot of time to get used to his English. If you ask me what we can prepare for in Taiwan, we should add the elements of understanding accents. We are used to listening to American English accents, but in the workplace, people don't speak like they do in textbooks. (Shen, submitted in week 11)

Chia described the way local Singaporeans spoke as a funny language style based on her experiences of communicating with her friend, a Chinese person who grew up in Singapore. When she talked to her friend in English, her friend produced sentences that were incomprehensible to her:

When we talked, sometimes I used Chinese... but my Singaporean friend liked to mix languages. Sometimes I have trouble understanding her sentences; she speaks Singlish. It is not just English. It is a strange language mixed in a funny way. I think I will gradually pick up some Singlish myself. (Chia, submitted in week 15)

Sentence Structure/Appropriate Usage. Using grammatically correct forms did not seem to be a major concern for these intern students at first. It was interesting that several students did notice their inability to produce grammatically correct English sentences; however, they claimed that ungrammatical, fragmented English expression did not interfere with their work performance.

The range hood was broken in the kitchen. No fried or sautéed food was available. That is about half of the food items. I worried that I didn't know how to explain this to them in detail. First, I don't know how to say "range hood" in English, and second, I don't know how to say "the restaurant doesn't have food that requires cooking with oil." But the customers arrived and started to order. So I said, "We don't have these. We cannot fry food, only steamed food." And I showed them the menu. In addition, I said, "The machine broke." I think my customers understood. Some said, "Oh, so no venting system." I also learned new vocabulary. (Yu, submitted in week 16)

Retrospectively, Yu reflected upon her experiences of not being able to speak a grammatically correct sentence in a situation that required her to provide detailed explanations. She said, "Sometimes, I know I might be talking about a situation where I needed to use the passive verb, but because I cannot recall the past participle form of 
the verb and the customer is waiting, I ended up having to use the active form."

Vocabulary and Terminology. In an internship context, the students needed to learn how the specific company operates:

I think I was a good student in Taiwan, but here, from time to time, I still didn't understand. Because of the MICE (Meeting, Incentive travel, Convention, Exhibition) events, we have had more international travelers meeting. I kept hearing people saying, "Go get some stools at the back of house." What exactly is "back of house"? Oh, he meant "storage room." That must be jargon I didn't learn at school. (Andy, week 14)

\subsubsection{Reading/Writing Difficulties}

Signing Contracts. Ching, who worked at the airport duty-free shop, mentioned only once at the beginning of her internship that her lack of reading and writing proficiency caused difficulties in her work environment:

I think the difficulties for me when I first arrived at Singapore were with the work contracts and rental lease. Teacher, can you help me go through the clauses? I don't quite understand the part regarding sick leave. (Ching, dialogue before the submission of her journal writing)

In answer to the first question (language or nonlanguage difficulties) and the second question (the most frequently mentioned skills), as shown in Figure 2, the mentions of language-related issues obviously surpassed the mentions of nonlanguage-related issues ( 94 vs. 35 times). Under the category of language-related issues, listening and speaking ( 84 times) were the problems they encountered most frequently as the primary concerns in their internship experiences.

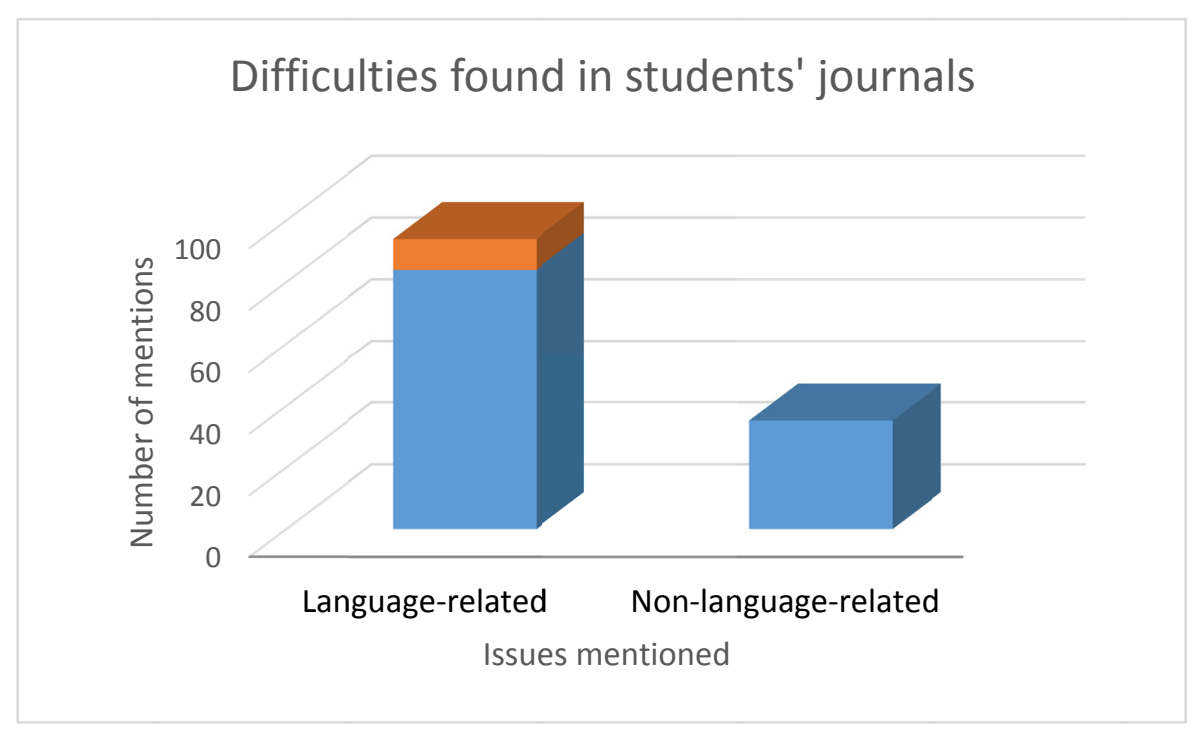

Figure 2. Categorization of difficulties

\subsection{Skills or Strategies Acquired}

\subsubsection{Language-Related Skills/Strategies}

Most of the students tried to improve their speaking and listening abilities; they invested this effort voluntarily. They needed to use these skills immediately in the workplace. Yu mentioned her strategies to improve her English grammar and usage: "I listened to how my co-workers, who were native English speakers spoke in a similar situation, and I tried to say the same thing next time." Yu self-assessed her listening ability by evaluating her interactions with Australians. Although she had setbacks, she realized that her listening ability was actually improving.

Ching, Chia, Andy and Shen mentioned that they googled the words to determine their meaning when they did not catch the meaning upon first encounter. Others attempted to leave an online message in the chat room to ask their language teachers back in Taiwan. 


\subsubsection{Nonlanguage-Related Skills}

\subsubsection{Problem-solving Skills}

Some wrote in their journals that it was gratifying to discover a new level of comfort in being able to handle their work alone. As Ching wrote in her journal, "Last week, the toilet wouldn't stop flushing. In Taiwan, I stayed at home. Everything was taken care of. Here, a running toilet really troubled me. I found an online video. It taught me how to fix easy problems with toilets. So, I removed the tank lid. I found out that it was the fill tube that fell off. I think I am more independent now." (Ching, submitted in week 4)

\subsubsection{Professional Service Skills}

\subsubsection{Increased Speed and Physical Strength}

Some intern students claimed that they became more attuned to the rapid pace of the service industry and were confident that they could be good servers. In week 14, Wei wrote that she barely recognized herself as she lost weight: "As a server in the restaurant, I constantly heard my manager saying how important service quality is. I try to achieve her standard. I need to practice carrying heavy loads of dishes without spilling, all the way from the kitchen to the hallway and to the customers' tables. You know how heavy a huge bowl of Chinese soup is? It is also dangerous; my co-worker got a burn from spilling the soup on herself. I also need to load and unload dishes from the dishwasher very quickly without chipping the delicate bowls or plates. I lost so much weight."

\subsubsection{Handling Customer Complaints}

Ching mentioned that she learned to control her temper and improve her customer-serving skills. "I helped the manager handle customer complaints at the airport. Sometimes I met wealthy Chinese women who are very angry. They were really outspoken and aggressive. I learned to calmly deal with each case. I learned to avoid mirroring their confrontational expressions. I took a deep breath, and I reacted with firm politeness. I cannot believe I am able to behave pleasantly but not submissively." (Ching, submitted in week 14)

\subsubsection{Attention to Detail}

Attention to detail is highly relevant in the service industry. One intern student described how she had witnessed a safety incident that clearly reminded her of the weight of her responsibilities as a waitress. Wei said, "One of my co-workers has had a customer who had an allergy to black peppers... there might be flecks of black peppers left. After several bites of his food, the Australian customer was sent to the hospital. I think that the cook did not put black peppers directly in his food, but the leftovers on the pot or something still caused the reaction. We work in the restaurant must always keep our workstations scrupulously clean." (Wei, submitted in week 14).

Regarding the questions of whether the intern students learned language or nonlanguage skills more frequently when working abroad and the kinds of skills/strategies that they learned, the answers are presented in Figure 3. The students reported learning language skills (98 mentions) more than other skills. Among the language skills/strategies, the primary skills acquired were related to speaking/listening ( 89 mentions). Professional skills (58 mentions) also appeared quite frequently in their journals.

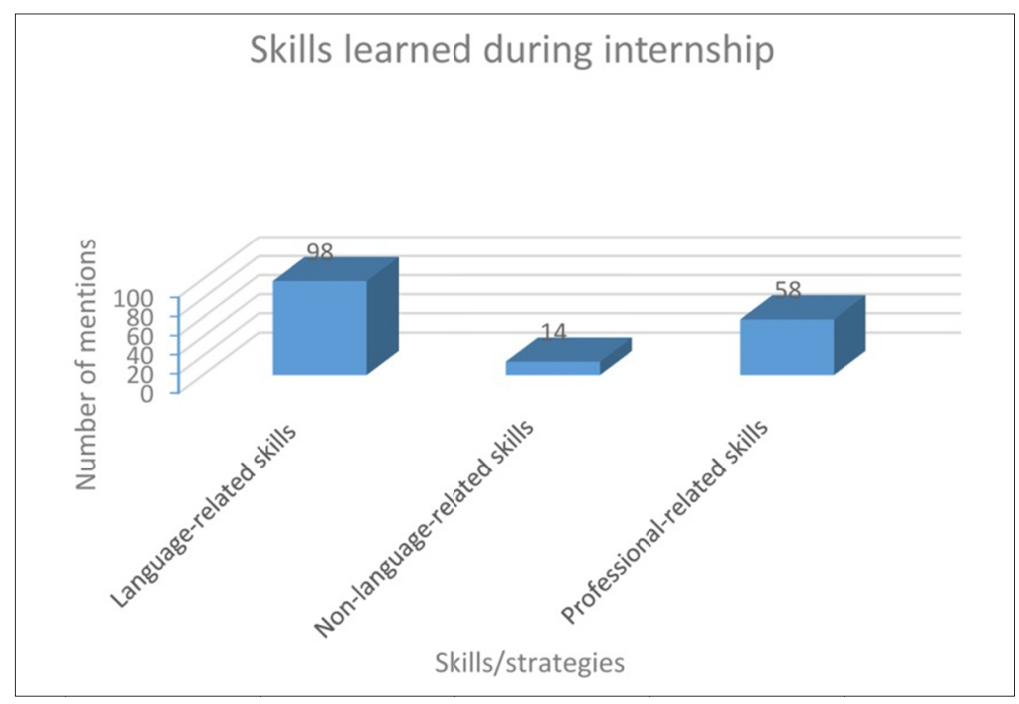

Figure 3. Categorizations of skills/strategies learned 


\subsection{Future Plans of Students}

A common thread found in the students' journals is that, at some point, the participants mentioned that they understood the value of interning abroad and that they would try to be more dedicated to developing work-related skills that would probably benefit them in the future. Exposure to another culture gave the students a different perspective about their future career. Ching mentioned that she wanted to work on an international cruise line, which requires good English proficiency.

\subsection{Preparing Taiwanese Learners of English for Working Abroad}

\subsubsection{Where Difficulties Arise}

Regarding the fifth question of whether English preparatory classes in Taiwan help students overcome language difficulties, their answers were not all positive. In many cases, the difficulties stemmed from a need to develop fundamental basics such as communicative listening and speaking abilities with customers, co-workers, and supervisors. Their difficulties arose when they were not aware of when to speak and when to listen and how to properly respond while going through each busy day with long work hours. Shen mentioned the following about talking to his supervisors:

I think from the body language and partly from the patience of my Indian supervisors, I had no problem understanding the instructions. In Taiwan, we put too much emphasis on reading. Communicating and reading body language is what we need.

When the intern students mentioned how previous classroom learning facilitated their internship overseas, most of them claimed that they could put into practice the concepts they read about in tourism and hospitality textbooks. However, with regard to language training, they noted that the typical Taiwanese classroom did not provide many useful practices to cope with real scenarios. The typical English classroom in Taiwan focused primarily on reading, and the class did not provide them with the skills needed to handle a variety of situations that may be confronted in the workplace.

\subsubsection{Authentic English Conversations}

As Andy once mentioned in his journal, the English conversation he heard in the hotel appeared to be more informal than the written English he read in textbooks. Andy believed that slang was an important aspect of the language for him to understand. The classroom teaching in Taiwan did not prepare him with the skills needed to master informal conversation. Andy thought that the authentic English he heard was littered with slang and idioms, one third of which were incomprehensible to him. He learned that in order to speak English like a native speaker, rich knowledge of English slang and idioms is essential.

\subsubsection{Practice English in an English Work Setting}

In general, they believed that their exposure to English made them more attractive as candidates for future employers. Combining work experience with language learning in an English-speaking country seemed to provide the students with a certain degree of confidence. Some said that they have been practicing workplace vocabulary in their own field, including learning elements such as how to be a better salesperson, waitress, or hotel housekeeper. Mostly, they thought that their actual interaction with English speakers throughout their work helped them to make better improvements in English than if they had stayed in their home country to intern in a similar job. Another exciting incentive to work in an English-speaking country was that they became acquainted with a new country and a new culture, which were experiences that they truly cherished.

For the last research question, regarding the extent to which students perceive that their work abroad supports their English learning, this issue is closely related to the students' personal motivation for learning English. Though motivation does not guarantee successful language learning, self-motivation seemed to reveal the possibility of intrinsic motivation. When staying in Singapore or Australia, the students reignited their motivation for learning English. Andy mentioned, "English helped me develop at the personal and professional level. I'd really like to be able to better express myself in English."

Most of the intern students mentioned, at some point, the practical reasons for learning English. Learning became a life goal for these students. Yu said, "In Taiwan, sometimes I just switched off learning mode as soon as I left the classroom." In vocational schools, students seek effortless, short-term solutions to exam-oriented English education. The reasons for failure or poor grades can often be traced to the absence of motivation to learn. Most students are satisfied with moderate levels of understanding and grades; for them, English may not be a communicative tool but just another subject or obligation. As soon as they leave the classroom, the channel for learning closes because they lack motivation. By contrast, in this study, the channel remained open even 
when these students were outside of the classroom because when they were in a foreign country, they were self-motivated to learn useful language skills.

Analyses of journal entries indicated that the intern students had the opportunity to interact socially with their co-workers, supervisors, and customers, but English improvement was less of a priority if their jobs did not require it. Even though the intern students prioritized work before studying, their self-declared improvements in English and personal growth can clearly be seen in all six students' reflective writing. Although rapid gains in English proficiency might not have occurred in the three-month period, most students obtained basic social skills in English to function in the workplace. The intern students could communicate in routine tasks requiring simple exchanges of information about familiar job matters.

However, when speaking of language difficulties and their language preparation in Taiwan, the students reported the need for more training and practice in listening and speaking. Some suggested that teachers should address the challenge of understanding different accents related to different linguistic backgrounds. Most Taiwanese students working abroad are likely to be in contact with people who are not native speakers of English. In addition, the Taiwanese students needed substantive intercultural skills that are demanded by today's global market. English-language internships always involve intercultural communication. Therefore, language learning and teaching should include cultural dimensions as a key component.

\section{Conclusions}

This study is subject to the caveats of a small number of participants, especially the limitation of knowing whether these six participants are typical of students in tourism and hospitality programs. Nonetheless, it could be argued that this study contributes to our understanding of students' efforts to learn to cope in a foreign country; in addition, the study also had value in highlighting what instructors in Taiwan should do to better prepare students for their internships abroad when designing an ESP course. A second limitation is that the data collection period might be too short. Longitudinal research is necessary to obtain and compare more comprehensive data along the English learning curve.

The tourism and hospitality job market are changing and will continue to change. The modern workforce requires adaptable students with an open attitude to continuously learn in their jobs. This study shows us that internships abroad helped students to strengthen their career goals in regard to gaining professional experience in their field of choice. Working abroad and engaging with locals in a professional environment brought these students a new type of growth that they could not have experienced in Taiwan. In the future, with a growing population of college students who work or intern abroad, researchers should seek more data sources that can add to the complexity and multiplicity of language learning research in professional settings outside of Taiwan.

\section{References}

Anderson, L., Boud, D., \& Cohen, R. (1995). Experience Based Learning in Understanding Adult Education. Sydney: Allen and Unwin.

Beard, C. (2006). Experiential learning: A handbook of best practice for education and trainers. UK, London: Kogan Page, Ltd.

Becket, N., \& Brookes, M. (2012). Developing global competencies in graduates. Journal of Hospitality, Leisure, Sport \& Tourism Education, 11, 79-82. https://doi.org/10.1016/j.jhlste.2012.02.007

Benson, P., Barkhuizen, G., Bodycott, P., \& Brown, J. (2012). Study abroad and the development of second language identities. Applied Linguistics Review, 3, 173-193. https://doi.org/10.1515/applirev-2012-0008

Brunton, M. W. (2009). An evaluation of hostel employees' attitudes to general and specific English in their coursework. ESP World, 8, 4.

Cairns, L. (2011). Learning in the Workplace: Communities of Practice and Beyond. In M. Malloch (Ed.), The SAGE Handbook of Workplace Learning. SAGE Publications. https://doi.org/10.4135/9781446200940.n6

CEDEFOP. (2008). Terminology of European Education and Training Policy: A Selection of 100 Key Terms. European Centre for the Development of Vocational Training. Office for Official Publications of the European Communities: Luxembourg.

Chen, Y. Y., \& Hsu, S. Y. (2007). An experiment and planning of curriculum for preparing practical competencies of hospitality management students. Asian Journal of Management and Humanity Sciences, 1(4), 577-589.

Dewey, J. (1933). How We Think: A Restatement of the Relation of Reflective Thinking to the Educative Process. 
DC Heath and Company: Lexington, MA.

Eraut, M. (2004). Informal Learning in the Workplace. Studies in Continuing Education, 26(2), $247-273$. https://doi.org/10.1080/158037042000225245

Eraut, M. (2011). Informal Learning in the Workplace: Evidence on the Real Value of Work-Based Learning (WBL). Development and Learning in Organizations, 25(5), 8-12. https://doi.org/10.1108/14777281111159375

Evans, K., \& Waite, E. (2010). Stimulating the innovation potential of 'routine' workers through workplace learning. Transfer: European Review of Labour and Research, 16, 243-258. https://doi.org/10.1177/1024258910364313

Evans, K., Waite, E., \& Kersh, N. (2011). Towards a social ecology of adult learning in and through the workplace. In M. Malloch, L. Cairns, K. Evans \& B. O’Connor (Eds.), The Sage handbook of workplace learning (pp. 356-370). London: Sage. https://doi.org/10.4135/9781446200940.n26

Gibbs, G. (2013). Learning by doing: A guide to teaching and learning methods. Oxford: Oxford Brookes University, Oxford Centre for Staff and Learning Development. Retrieved May 31, 2019, from https://thoughtsmostlyaboutlearning.files.wordpress.com/2015/12/learning-by-doing-grahamgibbs.pdf

Haggag, H. (2008). The effectiveness of a content-based program for developing English writing skills and languages proficiency of tourism and hospitality students. M.A. Dissertation. Egypt: Qena University.

Hall, R. (2009). Towards a fusion of formal and informal learning environments: The impact of the read/write web. Electronic Journal of E-Learning, 7, 29-40.

Holmes, V. L., \& Moulton, M. R. (1995). A contrarian view of dialogue journals: The case of a reluctant participant. Journal of Second Language Writing, 4, $223-251$. https://doi.org/10.1016/1060-3743(95)90011-X

Inozu, J., Sahinkarakas, S., \& Yumru, H. (2010). The nature of language learning experiences beyond the classroom and its learning outcomes. US-China Foreign Language, 8, 14-21.

Kirkness, A., \& Neill, L. (2009). Choosing texts for today's students: Do they understand the language? Journal of Hospitality, Leisure, Sport and Tourism Education, 8(2), 4-16. https://doi.org/10.3794/johlste.82.213

Knowles, M. S. (1950). Informal Adult Education, in Guide for educators based on the writer's experience as a programme organizer in the YMCA. New York: Association Press.

Laborda, L. G. (2009). Using web-quests for oral communication in English as a foreign language for tourism studies. Educational Technology \& Society, 12(1), 258-270.

Lantolf, J. P., \& Appel, G. (Eds.). (1994). Vygotskian approaches to second language research. Norwood, NJ: Ablex.

Lantolf, J. P., \& Thorne, S. L. (2006). Socio-cultural theory and the genesis of second language development. Oxford, UK: Oxford University Press.

Legutke, L., \& Thomas, H. (1997). Process and experience in the language classroom-Applied Linguistics and Language Study Series. UK: Longman Group Limited.

Leslie, D., \& Russell, H. (2006). The importance of foreign language skills in the tourism sector: A comparative study of student perceptions in the UK and continental Europe. Tourism Management, 27, 1397-1407. https://doi.org/10.1016/j.tourman.2005.12.016

Liu, Y., Xu, J., \& Weitz, B. A. (2011). The role of emotional expression and mentoring in internship learning Academy of Management Learning and Education, 10(1), 94-110. https://doi.org/10.5465/amle.10.1.zqr94

Lo, Y., \& Sheu, C. (2008). The design, implementation, and evaluation of an English tour guide project. The Asian ESP Journal, 4(2), 79-95.

Luka, I. (2009). Development of students' English for Special Purposes competence in Tourism studies at tertiary level. ESP World, 8, 4.

Martin, A., \& Davies, S. (2006). An evaluation of the language skills in Scottish hotels. Journal of Hospitality, Leisure. Sport and Tourism Education, 5(1), 4-15. https://doi.org/10.3794/johlste.51.94

Mason, J. (2002). Researching your own practice: From noticing to reflection. London: Routledge. https://doi.org/10.4324/9780203471876 
Mortensen, T., \& Walker, J. (2002). Blogging thoughts: personal publication as an online research tool. In A. Mortensen (Ed.), Researching ICTs in context (pp. 249-279). Oslo: Inter Media Report.

Nassaji, H., \& Cumming, A. (2000). What's in a ZPD? A case study of a young ESL student and teacher interacting through dialogue journals. Language Teaching Research, 4(2), 95-121. https://doi.org/10.1177/136216880000400202

Seibert, K. (1999). Role of reflection in managerial learning: Theory, research. USA, Westport, CT: Greenwood Publishing Group, Incorporated.

Strauss, A. L., \& Corbin, J. (1998). Basics of qualitative research: Techniques and procedures for developing grounded theory. Thousand Oaks, California: Sage Publications.

Vygotsky, L. S. (1978). Mind in society: The development of higher psychological processes (M. Cole, 1st ed.). Cambridge, MA: Harvard University Press.

Vygotsky, L. S. (1997). Educational psychology. Boca Raton, FL: St. Lucie Press.

Watkins, K., \& Marsick, V. (1990). Informal and Incidental Learning in the Workplace (1st ed.). London: Routledge.

Watkins, K. E., \& Marsick, V. J. (1992). Towards a theory of informal and incidental learning in organizations. International Journal of Lifelong Education, 11(4), 287-300. https://doi.org/10.1080/0260137920110403

Wilkinson, S. (2002). The omnipresent classroom during summer study abroad: American students in conversation with their French hosts. Modern Language Journal, 86, 156-173. https://doi.org/10.1111/1540-4781.00142

Zimmerman, E. (2011). Talk about language use: 'I know a little about your language.' In P. Benson \& H. Reinders (Eds.), Beyond the language classroom (2nd ed., pp. 88-105). Basingstoke, UK: Palgrave. https://doi.org/10.1057/9780230306790_8

\section{Copyrights}

Copyright for this article is retained by the author, with first publication rights granted to the journal.

This is an open-access article distributed under the terms and conditions of the Creative Commons Attribution license (http://creativecommons.org/licenses/by/4.0/). 